\section{ULTRASONOGRAPHY is now in SCIE}

\author{
Editor-in-Chief \\ ULTRASONOGRAPHY
}

We are pleased to announce that Ultrasonography is now listed in the SCIE category of the Web of Science hosted by Clarivate Analytics. Founded in 1982 as the official journal of the Korean Society for Ultrasound in Medicine, our journal has been striving globalization since its renewal as an English-language journal with full open access policy in 2014. As a result of our efforts to publish quality papers that comply with the latest editorial guidelines, we are listed in PubMed Central (2014), SCOPUS (2017) and now in SCIE.

Currently, more than half of the articles have been written by international authors over the past two years, and SCOPUS 'CiteScore $(=2.85$ for 2018$)$ is the highest among the all general medical ultrasound journals in the world. We expect the first official JCR (Journal Citation Reports) impact factor for 2019 to be around 3.0. In the future, we will continue to introduce the latest research and provide the most up-to-date guidelines for ultrasound imaging along with reviews that directly aid in actual clinical ultrasound.

As Editor-in-Chief, I would like to thank all the authors, reviewers and editors who supported our journal, especially the dedication and hard work of the staff who created the journal.

ORCID: Jeong-Sik Yu: https://orcid.org/0000-0002-8171-5838

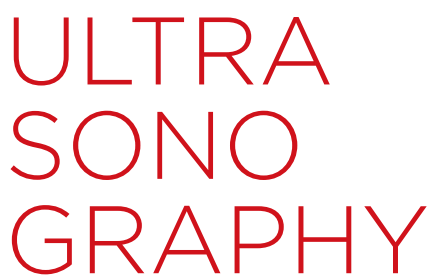

EDITORIAL

https://doi.org/10.14366/usg.19049 pISSN: 2288-5919 • elSSN: 2288-5943

Ultrasonography 2019;38:277

Received: September 24, 2019 Accepted: September 25, 2019
This is an Open Access article distributed under the terms of the Creative Commons Attribution NonCommercial License (http://creativecommons.org/ licenses/by-nc/4.0/) which permits unrestricted noncommercial use distribution, and reproduction in any medium, provided the original work is properly cited.

Copyright (C) 2019 Korean Society of Ultrasound in Medicine (KSUM)

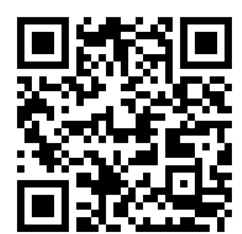

How to cite this article: Yu JS. ULTRASONOGRAPHY is now in SCIE. Ultrasonography. 2019 0ct;38(4):277.
Department of Radiology, Gangnam Severance Hospital, Yonsei University College of Medicine, 211 Eonju-ro, Gangnam-gu, Seoul 06273, Korea

Tel. +82-2-2019-3510, Fax. +82-2-3462-5472, E-mail: yjsrad97@yuhs.ac 